\title{
Characterization of a Mediterranean flash flood event using rain gauges, radar, GIS and lightning data
}

\author{
M. Barnolas ${ }^{2}$, A. Atencia ${ }^{1}$, M. C. Llasat ${ }^{1}$, and T. Rigo ${ }^{2}$ \\ ${ }^{1}$ Meteorological Hazards Analysis Team (GAMA) Department of Astronomy \& Meteorology Faculty of Physics, University \\ of Barcelona, Av. Diagonal 647, 08028 Barcelona, Spain \\ ${ }^{2}$ Meteorological Service of Catalonia, Generalitat de Catalunya, Spain Mercè Barnolas, Department of Astronomy and \\ Meteorology, Faculty of Physics, University of Barcelona, Av. Diagonal 647, 08028 Barcelona, Spain
}

Received: 8 February 2008 - Revised: 14 March 2008 - Accepted: 15 May 2008 - Published: 20 June 2008

\begin{abstract}
Flash flood events are very common in Catalonia, generating a high impact on society, including losses in life almost every year. They are produced by the overflowing of ephemeral rivers in narrow and steep basins close to the sea. This kind of floods is associated with convective events producing high rainfall intensities. The aim of the present study is to analyse the 12-14 September 2006 flash flood event within the framework of the characteristics of flood events in the Internal Basins of Catalonia (IBC). To achieve this purpose all flood events occurred between 1996 and 2005 have been analysed. Rainfall and radar data have been introduced into a GIS, and a classification of the events has been done. A distinction of episodes has been made considering the spatial coverage of accumulated rainfall in $24 \mathrm{~h}$, and the degree of the convective precipitation registered. The study case can be considered as a highly convective one, with rainfalls covering all the IBC on the 13th of September. In that day $215.9 \mathrm{~mm} / 24 \mathrm{~h}$ were recorded with maximum intensities above $130 \mathrm{~mm} / \mathrm{h}$. A complete meteorological study of this event is also presented. In addition, as this is an episode with a high lightning activity it has been chosen to be studied into the framework of the FLASH project. In this way, a comparison between this information and raingauge data has been developed. All with the goal in mind of finding a relation between lightning density, radar echoes and amounts of precipitation. Furthermore, these studies improve our knowledge about thunderstorms systems.
\end{abstract}

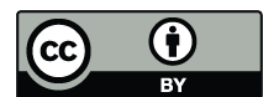

Correspondence to: M. Barnolas (barnolas@am.ub.es)

\section{Geographical location and temporal distribution of floods}

Floods are the major cause of loss of human lives and property damage in Catalonia (Llasat, 2004). Between 1901 and 2006, a total of 247 flood events have been identified, out of which more than 130 events lasted less than a day. The most frequent flood events are those produced by high intense local rainfalls during few hours over narrow coastal basins. Despite of this fact, Catalonia is also affected by catastrophic floods prompted by high amounts of rainfall accumulated that last more than $24 \mathrm{~h}$. In order to study rainfall events producing floods, this distinct behaviour has to be taken into account. This fact is clearly observable in Fig. 1, which shows the spatial distribution of floods occurred in the 20th century (Barnolas and Llasat, 2007) obtained using a GIS. The Maresme is the most affected basin (131 events in the last century), with 11 municipalities affected more than 10 times. This basin is usually affected by local flash floods producing road traffic cuts, loss of cars parked in the water courses and in some cases fatalities, as a consequence of the floods' suddenness. This kind of floods is associated with very convective rainfall events reaching high rainfall intensities over steep and narrow basins. These basins are located into the Internal Basins of Catalonia (hereinafter IBC), which include rivers that rise in Catalonia and flow into the Mediterranean Sea.

With regard to the monthly flood distribution (Fig. 2) flash floods are more frequent in summer and autumn where precipitation is mainly of convective origin. The high degree of convective precipitation during these seasons is caused by the combination of the presence of warm and moist air at low levels proceeding of the Mediterranean Sea, a complex topography of the region and a cold air mass at high levels.

Published by Copernicus Publications on behalf of the European Geosciences Union. 


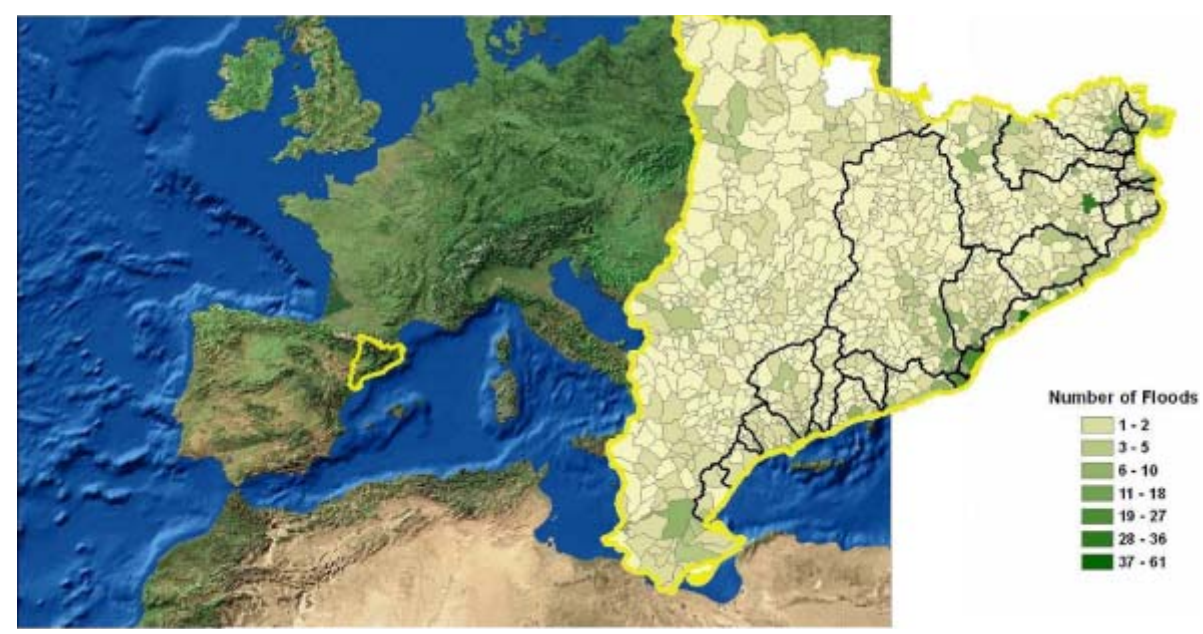

Fig. 1. Number of events by municipality. Black lines show the Internal Basins of Catalonia.

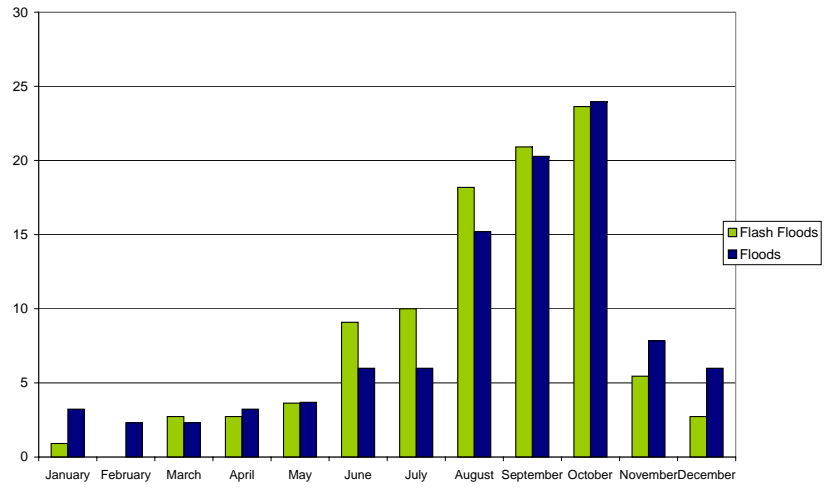

Fig. 2. Monthly distribution of floods.

\section{Pluviometrical analysis of events producing floods}

\subsection{Data and methodology}

The rainfall network of the SAIH (Automatic System of Hydrological Information) of the IBC has provided de pluviometric data. This network comprises 126 automatic stations distributed over the region, giving continuous information on accumulated rainfall at intervals of $5 \mathrm{~min}$. The meteorological radar has been used in order to classify the rainfall structures detected in each event. Radar data used in this work is obtained from the meteorological radar of Barcelona located at $20 \mathrm{~km}$ from Barcelona City. It belongs to the radar network of the Spanish Weather Service (INM). Its characteristics are shown in Table 1.

From the period 1996-2005, 67 heavy rainfall events have been detected in accordance with the four thresholds described in Table 2. Most of these events caused floods and serious damages.

In order to study heavy rains producing floods, it's interesting to distinguish between convective and stratiform pre-
Table 1. Characteristics of the INM meteorological radar in Barcelona.

\begin{tabular}{lll}
\hline Mode & Normal & Doppler \\
\hline Range & $240 \mathrm{~km}$ & $120 \mathrm{~km}$ \\
First elevation altitude & $0.5^{\circ}$ & $0.5^{\circ}$ \\
Number of levels & 20 & 8 \\
PRF & $250 \mathrm{~Hz}$ & $900 / 1200 \mathrm{~Hz}$ \\
Frequency & & $5600-5650 \mathrm{MHz}$ \\
Polarization & & Horizontal \\
\hline
\end{tabular}

Table 2. Thresholds used in order to select heavy rainfall events.

\begin{tabular}{l}
\hline Rainfall threshold \\
\hline $100 \mathrm{~mm} / 24 \mathrm{~h}$ in at least one raingauge \\
$60 \mathrm{~mm} / 24 \mathrm{~h}$ in 5 or more raingauges \\
$35 \mathrm{~mm} / 1 \mathrm{~h}$ in one or more raingauges \\
$200 \mathrm{~mm}$ in the entire event, in at least one raingauge \\
\hline
\end{tabular}

cipitation; this can be done using radar and rain gauge data. The parameter $\beta$ (Llasat, 2001) permits to obtain convective precipitation from rain gauge data.

This parameter is defined as:

$\beta_{L, \Delta T}^{*}=\frac{\sum_{N=1}^{i} I\left(t_{1}, t_{1}+\Delta T\right) \theta(I-L)}{\sum_{N=1}^{i} I\left(t_{1}, t_{1}+\Delta T\right)}$

in which $L$ is the intensity threshold $\Delta \mathrm{T}$ is the time-interval of accumulation of the precipitation, expressed in minutes $\mathrm{N}$ is the total number of $\Delta \mathrm{T}$ integration steps into which 

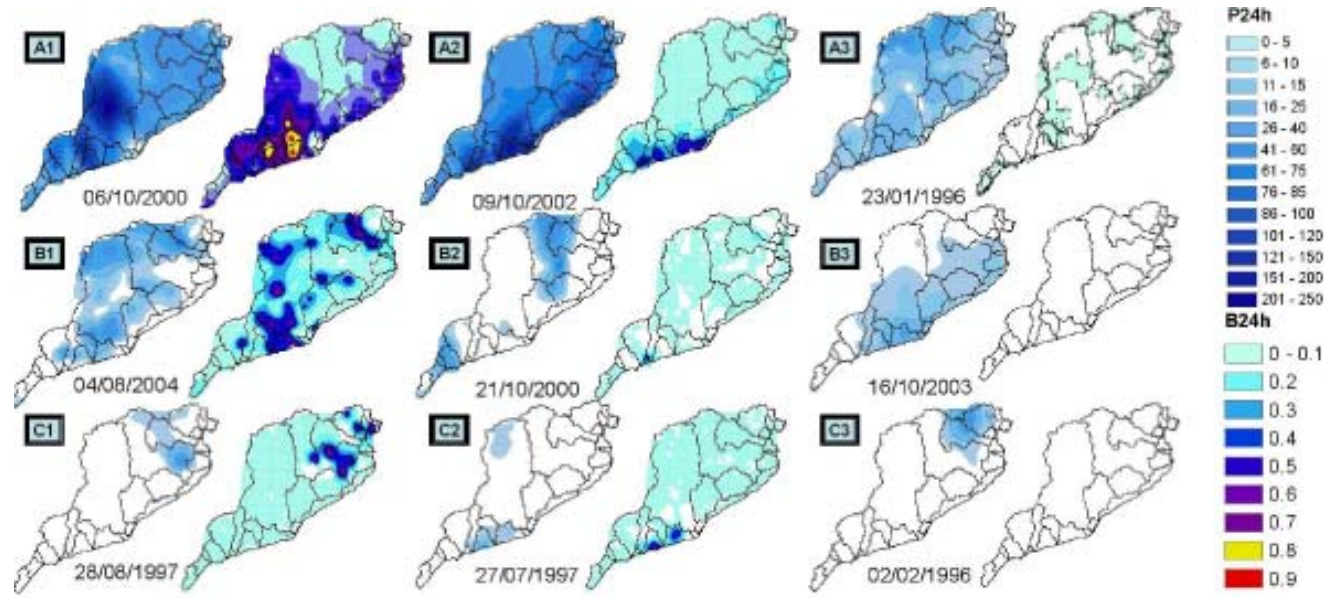

Fig. 3. $24 \mathrm{~h}$ accumulated precipitation and $\beta$ parameter fields for some examples of each event type.

Table 3. Different requirements used for identifying convective pixels in the 2-D algorithm.

\begin{tabular}{ll}
\hline $\begin{array}{l}\text { Procedure } \\
\text { name }\end{array}$ & $\begin{array}{l}\text { Requirements for } \\
\text { "convective" pixels }\end{array}$ \\
\hline Reflectivity & $\begin{array}{l}\mathrm{Z}>43 \mathrm{dBz} \\
\text { threshold }\end{array}$ \\
$\begin{array}{l}\text { Background reflectivity }\left(\mathrm{Z}_{b g}\right) \\
\mathrm{Z}-\mathrm{Z}_{b g}>(1 / \mathrm{a}) * \cos \left(\pi \mathrm{Z}_{b g} / 2 * \mathrm{~b}\right) \\
\text { Position }\end{array}$ & $\begin{array}{l}\text { The pixels adjacent to a convective } \\
\text { pixel are considered as convective }\end{array}$ \\
\hline
\end{tabular}

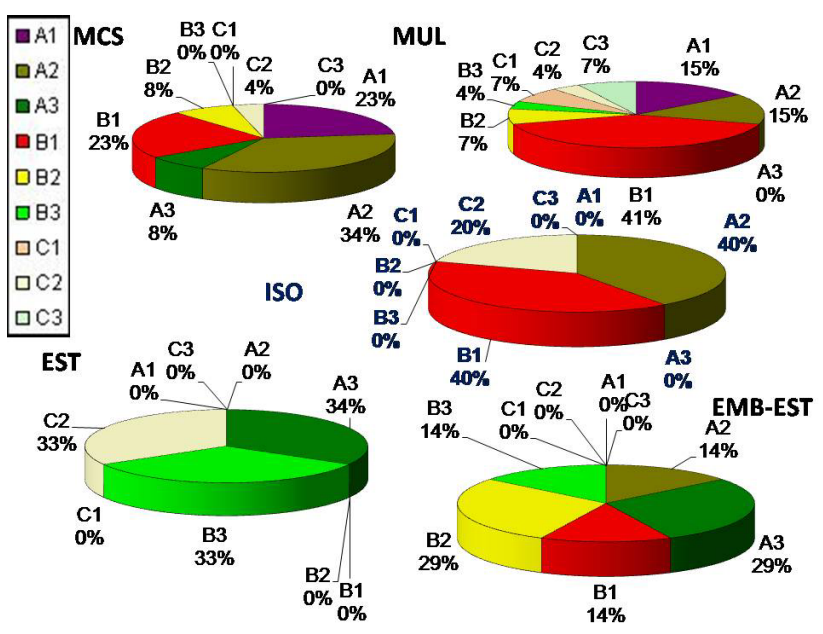

Fig. 4. Distribution of event type within each precipitation system type.

the episode is subdivided $\mathrm{I}\left(t_{i}, t_{i}+\Delta \mathrm{t}\right)$ is the precipitation measured between $t_{i}$ and $t_{i}+\Delta \mathrm{t}$ divided by $\Delta \mathrm{t}$, that is, the mean intensity in the said interval expressed in $\mathrm{mm} / \mathrm{min}$ or $\mathrm{mm} / \mathrm{h}$

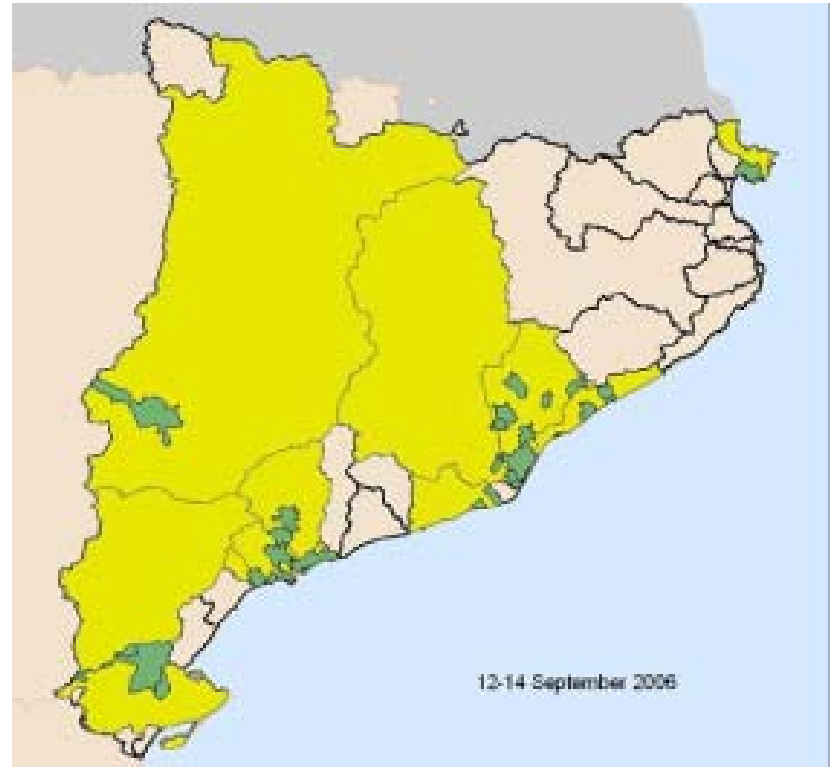

Fig. 5. Municipalities affected by floods on the $12-14$ September flash flood event.

$\theta$ (I-L) is the Heaviside function defined as:

$$
\begin{aligned}
& \theta(\mathrm{I}-\mathrm{L})=1 \text { if } \mathrm{I}>\mathrm{L} \\
& \theta(\mathrm{I}-\mathrm{L})=0 \text { if } \mathrm{I}<\mathrm{L} \\
& \theta(\mathrm{I}-\mathrm{L})=1 \text { if } \mathrm{I}=\mathrm{L}
\end{aligned}
$$

in which the last condition is imposed by the authors themselves.

The classification of precipitation structures attends to the degree of organization predominant in each radar image. In a first step, an identification of convective structures is done by applying the 2-D radar algorithms. The process to identify convective pixels considers three requirements that are independent one from another (see Table 3). One pixel is 


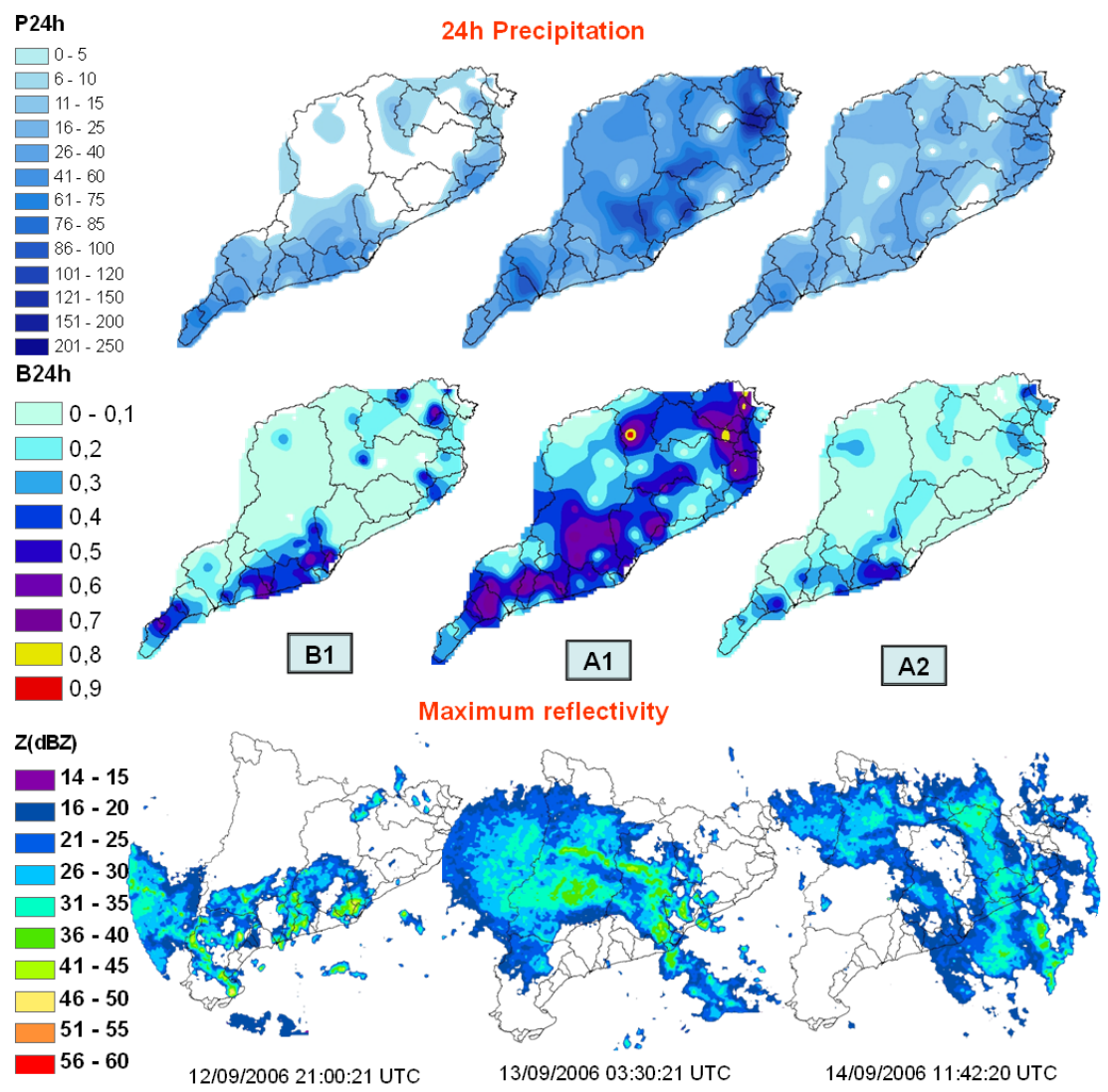

Fig. 6. $24 \mathrm{~h}$ accumulated precipitation, $\beta$ parameter and maximum reflectivity images for the 12-14 September 2006.

Table 4. Percentage of rain gauges with rainfall registered above $5 \mathrm{~mm} / 24 \mathrm{~h}$ (n5 (\%)), $\beta$ values used to distinguish between highly, moderate and slightly convective events. Number of days of each event type.

\begin{tabular}{llll}
\hline Type of event & $\mathrm{n} 5(\%)$ & $\beta$ & N. Days \\
\hline A1 & $>65 \%$ & $>0.7$ & $16(6.3 \%)$ \\
A2 & & $0.3 \leq \beta \leq 0.7$ & $35(13.7 \%)$ \\
A3 & $<0.3$ & $23(9.0 \%)$ \\
B1 & $15 \%<\mathrm{n} 5 \leq 65 \%$ & $>0.7$ & $49(19.2 \%)$ \\
B2 & & $0.3 \leq \beta \leq 0.7$ & $19(7.4 \%)$ \\
B3 & $<0.3$ & $13(5.1 \%)$ \\
C1 & $\leq 15 \%$ & $>0.7$ & $25(9.8 \%)$ \\
C2 & & $0.3 \leq \beta \leq 0.7$ & $19(7.5 \%)$ \\
C3 & & $<0.3$ & $56(21.9 \%)$ \\
\hline
\end{tabular}

considered convective if it verifies at least one of them. Once the three requirements have been applied to all pixels, those that do not verify any of them are considered as stratiform (for more information see Rigo and Llasat, 2004; and Ceperuelo et al., 2006). Once all the precipitation structures have been identified, their distribution, size, and duration are analyzed for each radar image. Taking into account these parameters the classification of rainfall structures is realized as follows:
Mesoscale Convective Systems (MCS): a precipitation structure could be identified as MCS when its major axis has a length equal or above $100 \mathrm{~km}$ during $3 \mathrm{~h}$ or more, and a minimum of a $30 \%$ of the area covered by it in each image can be associated to convective rainfall.

Multicelular structures (MUL): if the rainfall structure has a convective area exceeding the $30 \%$ of the total echo region, but does not meet the condition about time and size for being for an MCS.

Isolated convection (IND): when small scale, independent, and separated convective structures are identified.

Convective precipitation embedded into stratiform (ESTEMB): a stratiform region with some convective nucleous. The area covered by the convective precipitation does not exceed $30 \%$ of the total echo region.

Stratiform structures (EST): convective rainfall is not present.

\subsection{Classification of rainfall events}

After the analysis of all the heavy rainfall events recorded in the IBC between 1996-2005, the classification shown in Table 4 is proposed; it takes into account the extension of the precipitation field and the degree of convection. Figure 3 

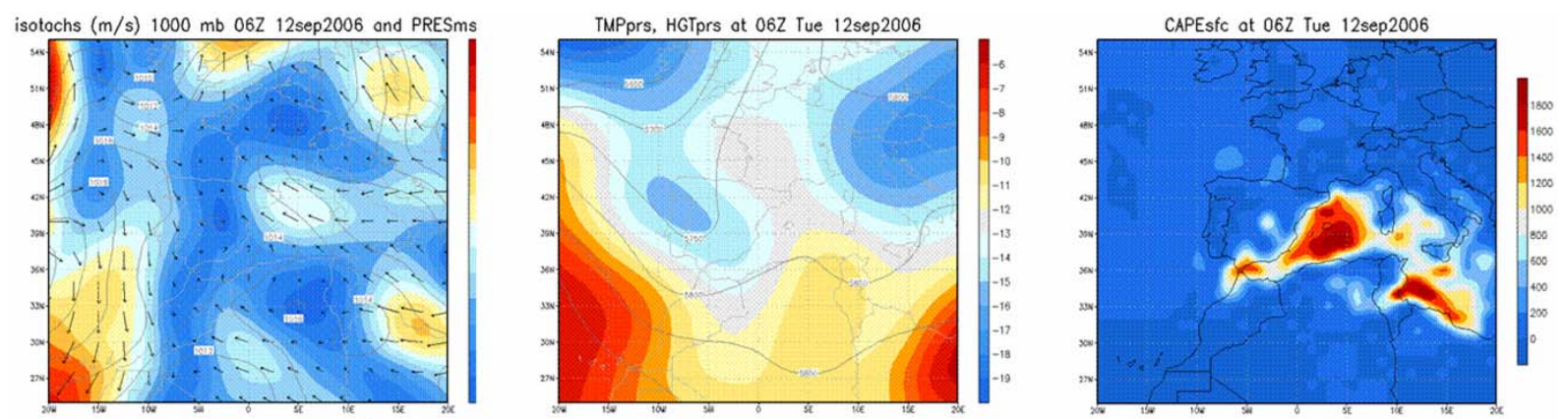

Fig. 7. MSLP and isotachs at surface (right), Geopotential height, Temperature at $500 \mathrm{hPa}$ (centre) and CAPE index on the Mediterranean Basin (right) for the 12 September 2006. Maps from the FNL-NCEP (Global Final Analyses from the National Centre of Environment Prediction).

shows the accumulated precipitation and the $\beta$ parameter fields in $24 \mathrm{~h}$ for an exemplar event of each one of these cases.

Considering the classification of precipitation structures proposed, each event in the study period has been labelled on the basis of the most important kind of precipitation system identified in it. The distribution of event type within each precipitation system type is shown in Fig. 4. All the treatment of rainfall data and radar information has been implemented with GIS.

\section{September 2006 event}

Between 12 and 14 September 2006, Catalonia (NE Spain) was affected by severe weather. More than $200 \mathrm{~mm} / 24 \mathrm{~h}$ and 5 -min intensities of $130 \mathrm{~mm} / \mathrm{h}$ were recorded in some places. The heavy rainfalls produced flash floods by the overflowing of a great number of ephemeral rivers, producing one casualty and several material damages valued at 73.11 million (municipalities affected by floods appear in green in Fig. 5). Together with the convective precipitation, other severe phenomena were observed, like two tornadoes, hail and a high lightning activity.

\subsection{Flood classification linkage}

This event has been selected for the following reasons: it is a typical autumn event producing flash floods in coastal basins, it belongs to the kind of precipitating systems which more usually produces floods and it is an episode with a high lightning activity. Taking into consideration the pluviometric classification proposed the event can be divided in three different types: B1 (12 September), A1 (13 September) and A2 (14 September) as it is shown in Fig. 6. Attending the classification of precipitation structures, MCSs are the most common structures producing floods (Rigo and Llasat, 2004). During the three days that the event lasted, different MCSs were detected, as it can be seen in the Zmax radar images (Fig. 6). The MCS's recorded were lineally organized convective structures, with trailing or leading stratiform area

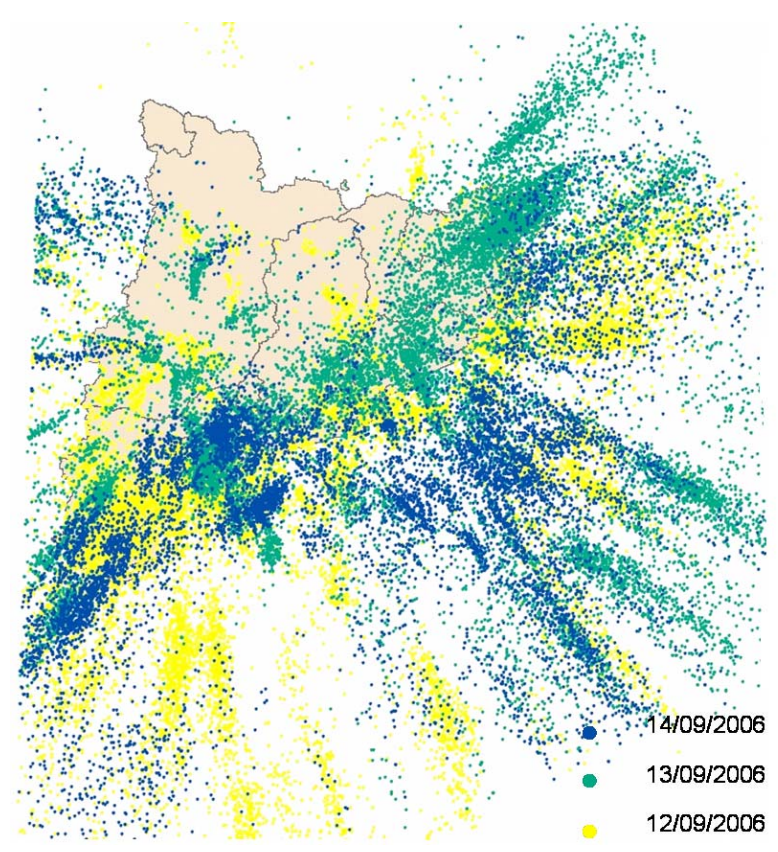

Fig. 8. Cloud-to-ground flashes recorded during the whole event (12-14 September 2006).

(Rigo and Llasat, 2007). Their movement was typical in this region, from $\mathrm{SW}$ to $\mathrm{NE}$, with their associated convective cells with a relative perpendicular movement (convective train). This kind of precipitation systems is more frequent in A1, B1, and A2 pluviometric events (Fig. 4).

\subsection{Synoptic situation}

On 12 September a relatively low pressure system was formed over Algeria. At the same time, a high pressure centre was located over central Europe (Fig. 7). Within this configuration the warm and wet air mass located in the Western Mediterranean basin was advected towards the littoral and the pre-littoral ranges of Catalonia. At upper levels, a 

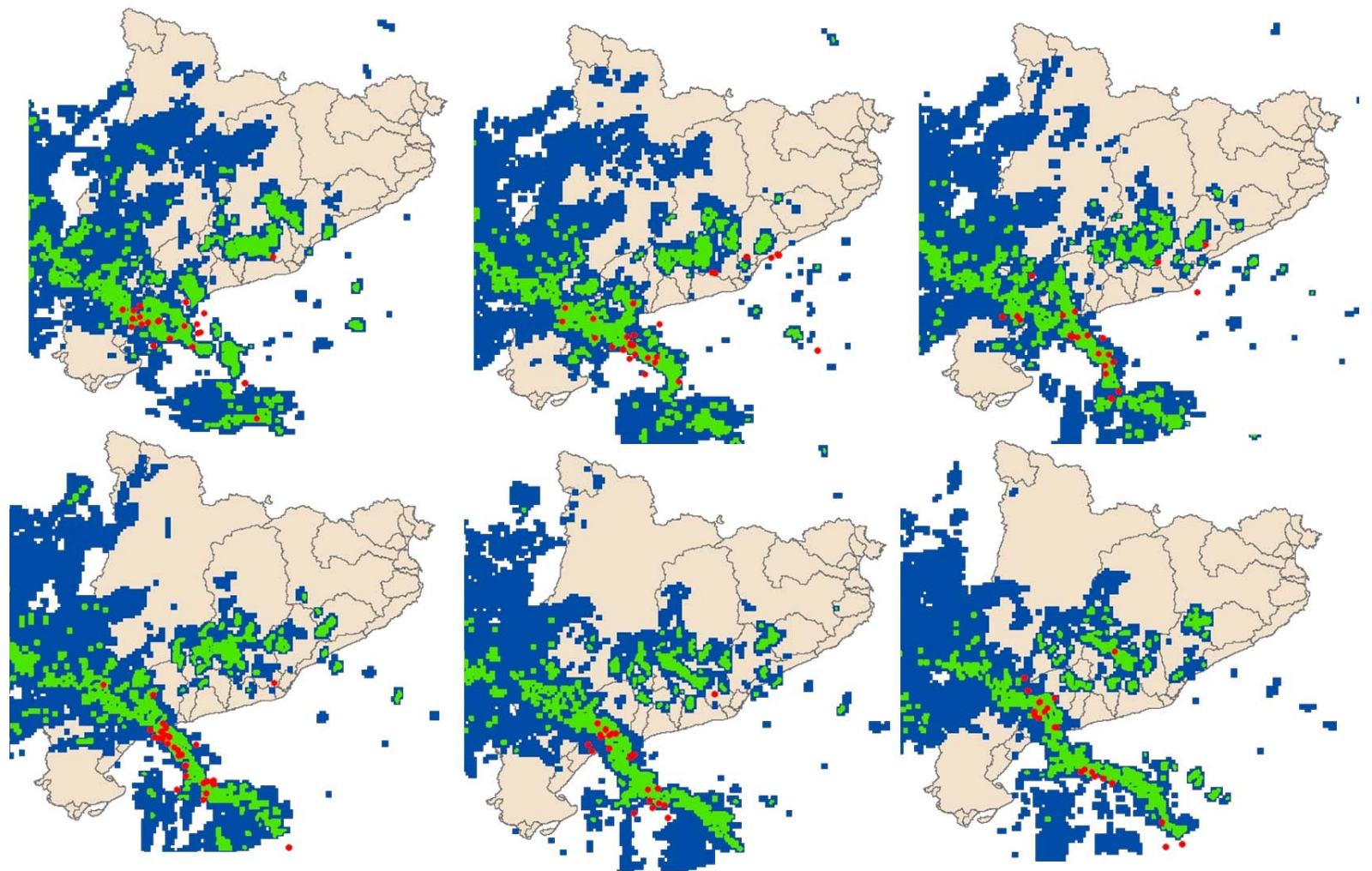

Fig. 9. 2-D identification of convective (in green) and stratiform (in blue) between 23:36 UTC (12 September) and 00:36 UTC (13 September). Cloud-to-ground flashes in the same interval have been superposed.

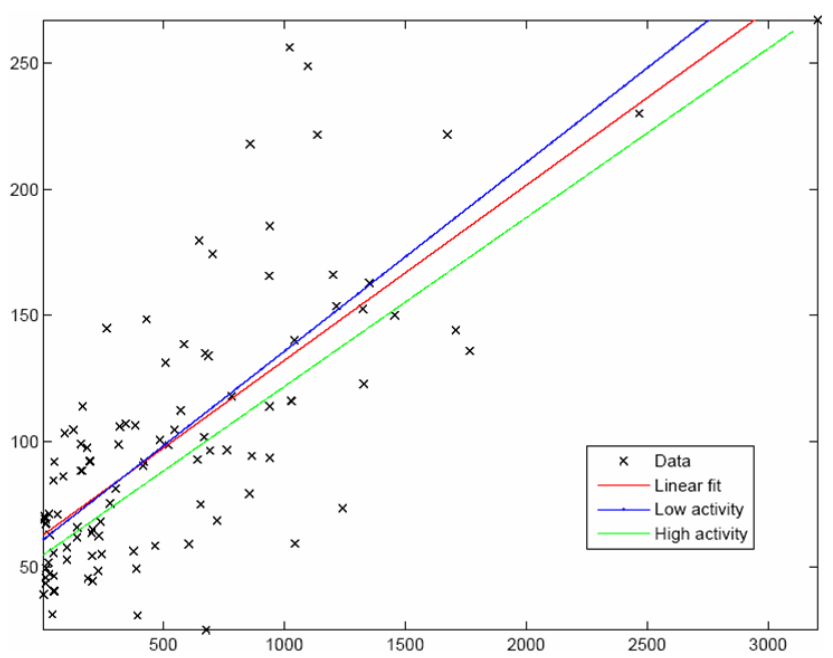

Fig. 10. Relation between number of lightnings and rainfall amount: for all lightning data (in red), high (in green) and low (in blue) lightning activity.

trough was located at the vertical of the Iberian Peninsula providing high instability over the North-East Iberian Peninsula. In addition, high values of CAPE index were present all around the Western Mediterranean, implying large amounts of available energy in the middle and upper tropospheric levels. As a result, heavy precipitation was recorded during the event.

\subsection{Radar and lightning analysis}

The study case was an episode with a high lightning activity. Near 184000 flashes, of which 58052 were cloud-to-ground (Fig. 8), were recorded during the whole event. Flashes were detected by the XDDE (lightning detection network from the National Weather Service of Catalonia).

After applying the 2-D radar algorithms, convective and stratiform precipitation was identified between 23:36 UTC (12 September) and 00:36 UTC (13 September). In Fig. 9 lightning data detected in the same interval has been superposed to the 2-D identification. The leading line of high reflectivity (a well-defined squall line) is characterized by a preponderance of cloud-to-ground strikes. In the interval selected, 2318 cloud-to-ground lightnings were detected.

The relation between lightning's number and rainfall's amount is also studied. Flashes are counted within a $6 \mathrm{~km}$ radius of a particular rain gauge over a time interval of $30 \mathrm{~min}$. Firstly, a general relation for the entire dataset has been studied $(r=0.61)$. After that, high and low lightning activity are studied separately to investigate if a better relation exists between these two fields. Lightning activity 


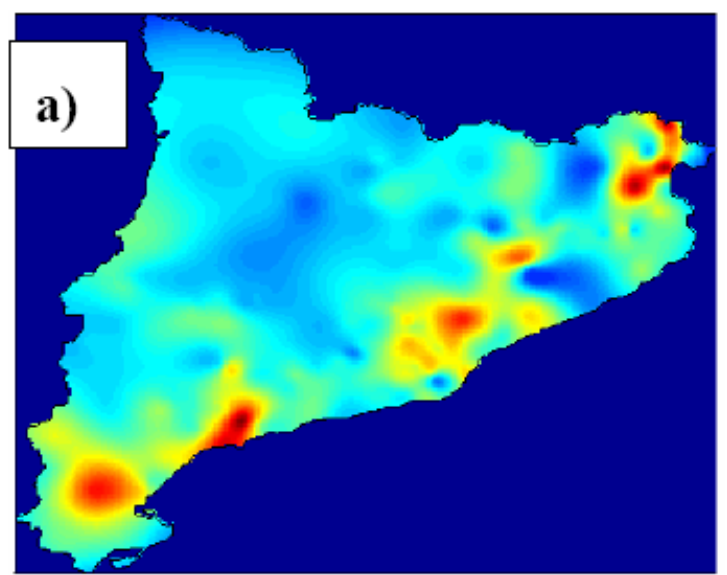

Precipitation (mm)

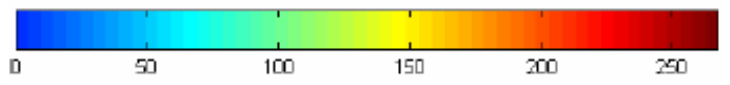

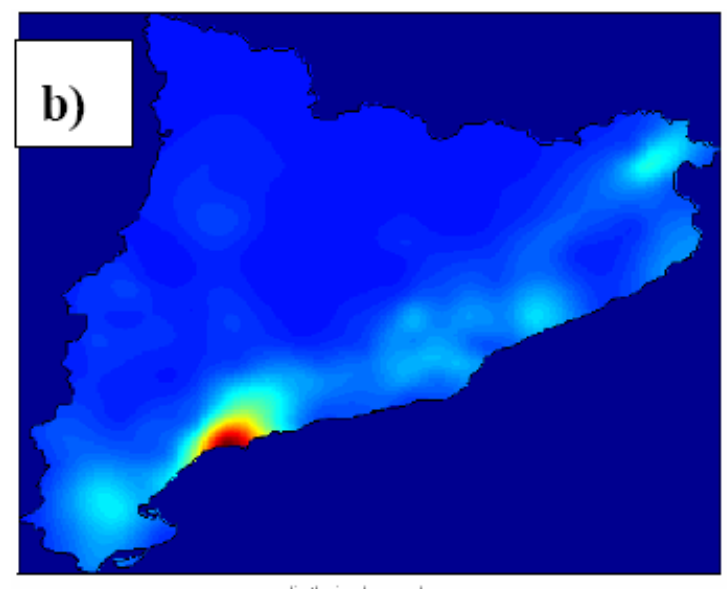

ligthning's number

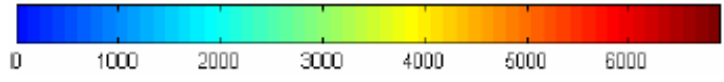

Fig. 11. (a) Accumulated rainfall over Catalonia from 12 September 2006 at 00:00 UTC to 15 September 2006 at 00:00 UTC, (b) Total number of lightning

is considered to be high if more than 1000 cloud-to-ground strikes are counted within a certain rain gauge influence's circle. High activity improves the linear fit $(r=0.78)$, showing the higher lightning activity is, the more intense precipitation is (or more convective). This result is due to the fact that both of them are associated with high vertical velocities. However low activity shows a poor relation between rainfall and flashes $(r=0.46)$, as it is shown in Fig. 10. This poor result could be related to the variability of rain regimes in this dataset. Low activity, less than 1000 discharges, can appear in stratiform precipitation regions in the same way as in convective ones. The different physic nature of these kinds of precipitation causes this inconsistence rate between rain and lightning activity.

Figure 11 compares graphically the accumulated rainfall over Catalonia from 12 September 2006 at 00:00 UTC to 15 September 2006 at 00:00 UTC compared with the total number of lightnings in the same period. A great spatial correlation is shown between both fields over Tarragona (the south coast of Catalonia, Spain).

\section{Conclusions}

The high number of heavy rainfall events leaning to floods in Catalonia has led to the need to obtain a methodology to classify them on the basis of their rainfall distribution at the surface and their degree of convection. A flash event from FLASH project has been selected to validate the classification. The main flash floods were produced on the 13 September 2006 in the framework of an A1 event by a linear MCS and some convective trains generated on the coast. Its high lightning activity has made it suitable to study the relation between strikes and precipitation, finding that this relation is improved when there is high lightning activity. Future work will contemplate the application of this classification to other flood events. Other polynomial tests will be used to find a better lightning-precipitation relation.

Edited by: A. Mugnai

Reviewed by: one anonymous referee

\section{References}

Barnolas, M. and Llasat, M. C.: A flood geodatabase and its climatological applications: the case of Catalonia for the last century, Nat. Hazards Earth Syst. Sci., 7, 271-281, 2007, http://www.nat-hazards-earth-syst-sci.net/7/271/2007/.

Ceperuelo, M., Llasat, M. C., and Rigo, T.: Rainfall events and hailstorms analysis program (RHAP), Adv. Geosci., 7, 205-213, 2006, http://www.adv-geosci.net/7/205/2006/.

Llasat M. C.: An objective classification of rainfall events on the basis of their convective features: Application to rainfall intensity in the north-east of Spain, Int. J. Climatol., 21, 1385-1400, 2001.

Rigo, T. and Llasat, M. C.: A methodology for the classification of convective structures using meteorological radar, Nat. Hazards Earth Syst. Sci., 4, 59-68, 2004, http://www.nat-hazards-earth-syst-sci.net/4/59/2004/.

Rigo, T. and Llasat, M. C.: Analysis of mesoscale convective systems in Catalonia using meteorological radar for the period 1996-2000, Atmos. Res., 83, 458-472, 2007. 